\title{
A diabetic life before and after the insulin era
}

\author{
J. M. Brostoff $\cdot$ H. Keen $\cdot$ J. Brostoff
}

Received: 8 July 2006 / Accepted: 27 October 2006 / Published online: 11 April 2007

(C) Springer-Verlag 2007

To the Editor: Before the introduction of insulin, a person with acute-onset diabetes had a short life expectancy and died in ketoacidosis. We report the case of our greatgrandfather (J. M. Brostoff) and grandfather (J. Brostoff) respectively, who was diagnosed with acute-onset diabetes in 1909, at the age of 29 years. He survived by diet treatment alone, aided by strength of will, for 14 years, and was one of the first patients in the UK to receive insulin in August 1923; the first British-made insulin having been released in July of that year. He lived to the age of 88 years,

Electronic supplementary material The online version of this article (doi:10.1007/s00125-007-0641-0) contains supplementary material, which is available to authorised users.

\section{J. M. Brostoff}

Central Middlesex Hospital,

London, UK

H. Keen

Unit for Metabolic Medicine, Department of Diabetes, Endocrinology and Metabolism, Guys Hospital Campus,

Kings College,

London, UK

J. Brostoff

Diet and Gastrointestinal Health Research Group,

Franklin Wilkins Building, Kings College,

London, UK

\section{Present address:}

J. M. Brostoff

Department of Medicine, Sir Charles Gardiner Hospital,

Perth, WA, Australia

\section{Present address:}

J. Brostoff $(\bowtie)$

34 Fitzjohns Avenue,

London NW3 5NB, UK

e-mail: j.brostoff@virgin.net in robust health, and with no overt signs of microvascular or macrovascular pathology.

In 1909 a previously lean healthy 29 -year-old, $186 \mathrm{~cm}$ tall, presented to his general practitioner with a 3-month history of polydipsia, polyuria and weight loss. A urine sample immediately turned brick red when boiled with Benedict's solution, and a diagnosis of diabetes mellitus was made. The patient was informed that his life expectancy was limited, and that he should 'make arrangements'. As a father of five young children (none of whom subsequently developed diabetes), he was determined to fight the disease, even though at that time the life expectancy for patients with acute onset diabetes was less than 4 years from diagnosis (Fig. 1) [1].

His first step was to travel to see the Kaiser's physician in Berlin, who prescribed a strict diet with dramatically reduced carbohydrate content, whereas fat intake was greatly increased. He was advised to eat fried bacon because of its high fat content and, despite his Jewish faith, carried this out. As a result he lost $32 \mathrm{~kg}$ in weight. $\mathrm{He}$ was also advised to make annual visits to $\mathrm{Bad}$ Neuenahr-am-Rhein, where the waters were said to be especially beneficial for people with diabetes. Here he regained $3 \mathrm{~kg}$ until he had to return to the UK rather quickly when war broke out in 1914 .

His health slowly deteriorating, he went on the Allen diet. This rigorous regimen involved restriction of total food energy intake to $1,000 \mathrm{kcal}(4,190 \mathrm{~kJ})$ per day, with an added weekly 36-h fast. Although this brought him to the brink of collapse, he would still retire to bed on a Saturday evening with a flask of coffee, and appear again on Monday morning. However, he did have to give up his work as a tailor for a period. Following consultation with Dr Otto Leyton in 1916 his diet was changed to one that was absolutely sugar-free, and he was able to resume his 
Fig. 1 The increasing life expectancy (years) of diabetic patients attending the George Baker Clinic in Boston (MA, USA) from 1897-1945 analysed by the Metropolitan Life Insurance Company. The data exclude deaths within 1 week of first observation or hospital discharge. It can be seen that the subject of this case report had an expected lifespan of only 4.1 years from the time that he was diagnosed with diabetes in 1909

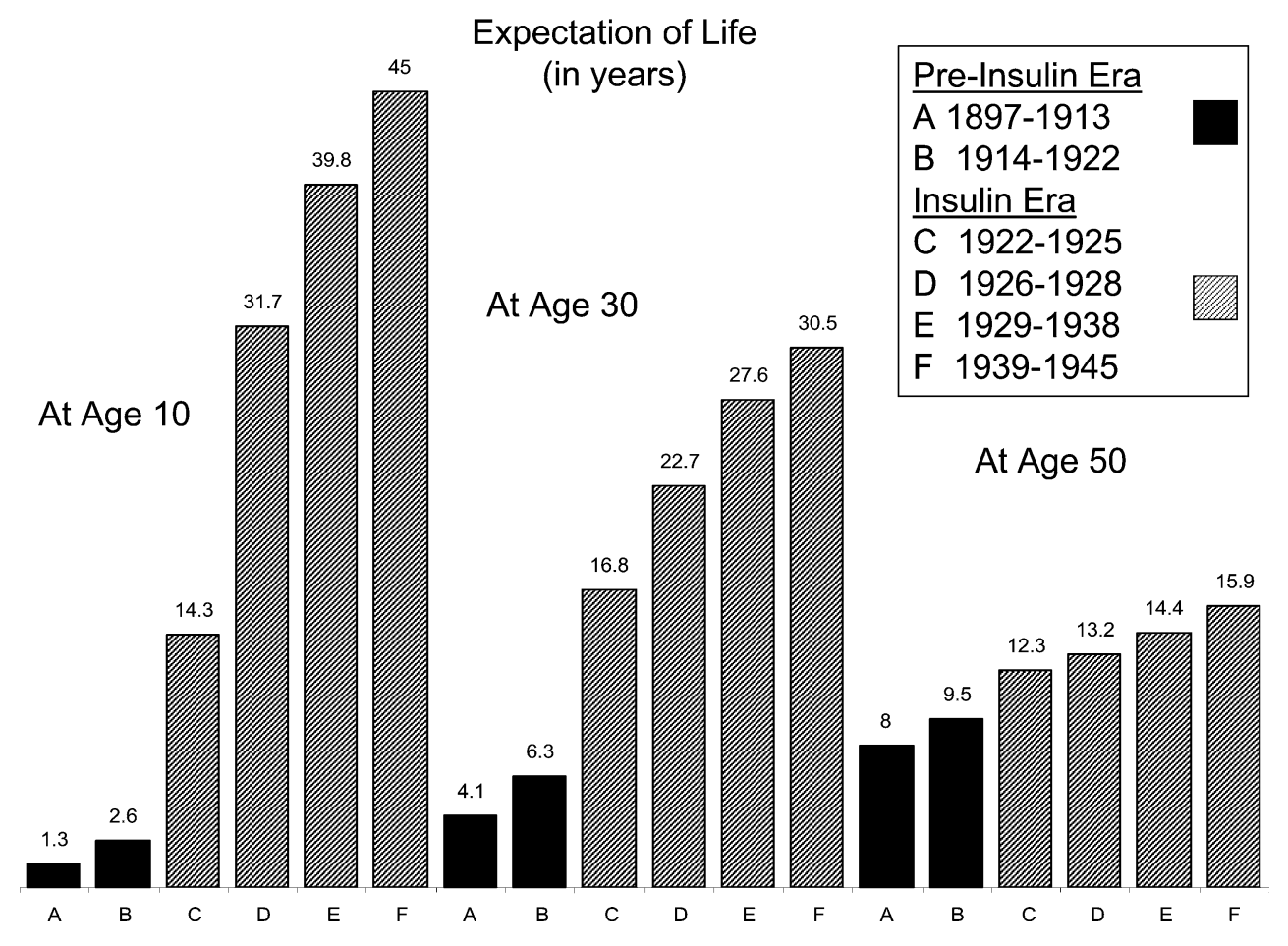

occupation. From 1918 onwards he maintained the lowenergy diet without the fasting. His weight gradually fell from 82 to $64 \mathrm{~kg}$, but he managed to keep working. In 1919 he collapsed as a result of the meagre diet and attempts at continuing to work. Even on a more strict diet, he had continual 'symptoms of impending coma' (Electronic supplementary material [ESM] Fig. 1).

In 1921 he returned to Bad Neuenahr for further treatment, but his condition deteriorated even further. Profoundly weak, he travelled with an escort to Frankfurt-amMain to seek the advice of Professor Carl von Noorden, who was known as the 'Zucker Gott'. This clinic was organised along the lines of a first-class hotel, with 100 bedrooms. Nonetheless, after 7 months he was sent home on a stretcher to die, weighing little more than $37 \mathrm{~kg}$. A photograph reveals a skeleton over which the skin is tightly stretched. An increase in carbohydrate intake brought some improvement, allowing him to put on weight even though he was unable to continue to work. He managed to survive this way until 1923. It is noteworthy that Professor von Noorden had tried insulin treatment late in 1922, but decided that it had only transient effects and discontinued its use.

On 7 August 1923 the patient was admitted to The London Hospital under the care of Dr Leyton. On admission his weight was $49 \mathrm{~kg}$, he had glycosuria and ketosis, and his blood sugar was $0.3 \%$ (300 mg/dl, $17 \mathrm{mmol} / \mathrm{l})$. Insulin was started at a dose of 20 units per day, and his daily food allowance was increased to $1,330 \mathrm{kcal}(5,580 \mathrm{~kJ})$. Over the next 5 weeks of his hospital stay his weight climbed to $57 \mathrm{~kg}$ and his urine became free from glucose and ketones.
At discharge, his blood sugar was recorded as $0.14 \%$ $(1,400 \mathrm{mg} / \mathrm{dl}, 78 \mathrm{~mol} / \mathrm{l})$ and his dietary energy intake had been increased to $1,520 \mathrm{kcal}(6,360 \mathrm{~kJ})$ per day.

His care was taken over by Dr R.D. Lawrence of King's College Hospital. The patient opted to continue with three daily injections of soluble insulin despite the introduction of longer-acting insulin preparations. He felt secure with a regimen with which he was familiar (and one, incidentally, followed lifelong by his physician, Dr Robin Lawrence). He was meticulous in the control of his blood sugar, and gave himself more than 47,000 injections during his lifetime. He travelled extensively, and was an active social worker and committee member of the British Diabetic Association. In 1959 he was awarded a Joslin Victory Medal for surviving 50 years with diabetes (ESM Fig. 2), which states:

$$
\begin{gathered}
\text { For } \\
\text { prolonging life's span } \\
\text { after the } \\
\text { onset of diabetes } \\
\text { a } \\
\text { scientific and moral victory }
\end{gathered}
$$

By the time of his death at the age of 88 years he had suffered no overt microvascular or macrovascular complications of diabetes.

By 1979 the Joslin Diabetes Centre had awarded only 338 50-year survival medals throughout the world, including 38 in England. There may have been a genetic element in his long survival, for studies of patients surviving more 
than 50 years of treated diabetes have shown that they share certain characteristics, including absence of hypertension, a near-normal BMI, a relatively low insulin requirement and parental longevity. A recent study of 400 long-term type 1 diabetic patients in the UK also showed very high HDL levels; $66 \%$ of participants had levels above the reference range, and it is suggested that HDL levels may be useful as a prognostic marker in type 1 diabetes [2].

An alternative possibility is that he did not in fact have type 1 diabetes. He was never overweight, which makes early diagnosis of type 2 diabetes unlikely, and the absence of a family history of diabetes would exclude the possibility of maturity-onset diabetes of the young [3]. The classic acute presentation in 1909, and subsequent recordings of ketonuria (although sometimes in the context of fasting) would support a diagnosis of type 1 diabetes. He must nevertheless have preserved some insulin secretory function after diagnosis to account for his prolonged survival, an example perhaps of Latent Autoimmune Diabetes of the Adult (LADA) [4].

His survival free of overt vascular complications might also be attributed to his physically active life, a BMI well within the normal range, and very tight control of his blood sugar with insulin injections three or more times daily [5]. A family anecdote concerns one of his long-haul flights, which crash landed, fortunately with no casualties. Once on the tarmac he immediately took his insulin and sat down and had his packed meal, which he always took with him on such journeys in case of an emergency!

Acknowledgements We are grateful to Professor A. Hattersley (Peninsula Medical School, Exeter, UK) for his comments and to J. Evans, the archivist at the Royal London Hospital, for finding the original inpatient records of the patient.

\section{References}

1. Joslin EP (1947) The unknown diabetic. Postgrad Med J 302-306

2. Bain SC, Gill GV, Dyer PH et al (2003) Characteristics of type 1 diabetes of over 50 years duration (the Golden Years Cohort). Diabet Med 20:808-811

3. Fajans SS, Bell GI, Polonsky KS (2001) Mechanisms of disease: molecular mechanisms and clinical pathophysiology of maturityonset diabetes of the young. New Engl J Med 345:971-980

4. Pozzilli P, Di Mario U (2001) Autoimmune diabetes not requiring insulin at diagnosis (latent autoimmune diabetes of the adult): definition, characterization, and potential prevention. Diabetes Care 24:1460-1467

5. Diabetes Control and Complications Trial Research Group (1993) The effect of intensive treatment of diabetes on the development and progression of long-term complications in insulin-dependent diabetes mellitus. N Engl J Med 329:977-986 